\title{
Intensification of Synthesis of Fatty Acid Isopropyl Ester using Microwave
}

\author{
Amrina Maulida ${ }^{1}$ Zahrati $^{1}$, Hilyati Kamila ${ }^{1}$, Teuku Mukhriza ${ }^{1}$, Asri Gani ${ }^{1}$, \\ Muhammad Dani Supardan ${ }^{*}$ \\ ${ }^{1}$ Department of Chemical Engineering, Engineering Faculty, Universitas Syiah Kuala, Jl. Syech Abdurrauf No. \\ 7, Darussalam, Banda Aceh, 23111, Indonesia
}

\begin{abstract}
Fatty acid isopropyl ester is one of the derivative products from vegetable oils such as crude palm oil (CPO). Chemically, fatty acid isopropyl esters can be synthesized from oils or vegetable fats with isopropanol using inorganic catalysts. The purpose of this research was to intensify the process of synthesis of fatty acid isopropyl esters from CPO using microwaves. Research variables used were CPO to isopropanol molar ratios of 1:3, 1:5, 1:7, 1:9, 1:11, and 1:13; reaction times of 1,3 , and 5 minutes; and $\mathrm{KOH}$ catalyst concentrations of $0.10,0.15,0.20$, and 0.30 (\%-w of CPO). The experimental result showed that the process variables affected the yield of fatty acid isopropyl esters. The highest yield obtained $(80.5 \%)$ was found at molar ratio of CPO to isopropanol of $1: 11$, catalyst concentration of $0.2 \%$ (\%-w of CPO), and reaction time of 5 minutes. With the same conditions, a 72.2\% yield was obtained in 150 minutes using conventional transesterification. Fourier transform infrared analysis showed some specific functional groups in fatty acid isopropyl esters. In addition, viscosity, density, and acid number of fatty acid isopropyl esters produced conformed to the Indonesian National Standard (SNI) No. 7182-2015.
\end{abstract}

Keywords: CPO; Fatty acid isopropyl esters; Microwave; Transesterification

\section{Introduction}

The use of vegetable oil is highly prevalent in Indonesia due to its abundant availability. The development of oleochemical industries that produce derivative products from vegetable oils is still largely at a prospective stage and needs to be strengthened to increase the economic value of the resource. Following such development, it is hoped that the derivative product of vegetable oil will not only meet domestic needs but will also become an important Indonesian export commodity.

One of the potential derivative products of vegetable oil is fatty acid isopropyl esters. Fatty acid isopropyl esters are in great demand because these fatty acids can be used as raw materials for various products, such as cosmetics, foods, pharmaceuticals, bio-lubricants, and bio-solvents (Seo et al., 2018). Crude palm oil (CPO) is one of the potential raw materials that can be used for the production of fatty acid isopropyl esters. At present, Indonesia is the largest producer and exporter of CPO in the world. However, the economic value obtained from CPO is still not optimal. The processing of CPO to its derivative products, which have a higher selling value, must be conducted to optimize the economic value of CPO in Indonesia.

Several technological processes for the production of fatty acid alkyl esters have been

${ }^{*}$ Corresponding author's email: m.dani.supardan@unsyiah.ac.id, Tel.: +62-81360699722 doi: 10.14716/ijtech.v11i3.3513 
developed. The chemical transesterification process is the most widely used process for the synthesis of fatty acid alkyl esters such as fatty acid isopropyl esters (Supardan et al., 2017; Cercado et al., 2018). However, chemical transesterification using the conventional process has some shortcomings such as long reaction times and considerably severe operating conditions making such reaction an energy-intensive process. Alternative processes, such as the use of microwaves (Ye et al., 2016) and ultrasonic and hydrodynamic cavitation (Laosuttiwong et al., 2018) can be used to intensify the fatty acid alkyl ester production process.

Microwaves are a non-conventional energy source, which has been used for a variety of applications including chemical synthesis. Several researchers have reported the advantages of using microwaves compared to conventional methods, including Encinar et al. (2012) and Teo and Ani (2014). The intensification of the transesterification process using microwaves was had also been explored in prior research. For example, Dehghan et al. (2019) reported the use of microwaves to accelerate the transesterification of inedible olive oil for biodiesel production, and Yu et al. (2017) used the synergistic microwaveultrasonic irradiation for the transesterification of soybean oil.

This study aims to intensify the synthesis process of fatty acid isopropyl ester from CPO using $\mathrm{KOH}$ as an alkaline catalyst through the use of a built-in microwave. Presently, there is limited information in the published literature on the intensification process concerning the processing of CPO to its derivative products. To address this research gap, we will compare the performance of the synthesis process using microwaves to that of the conventional processes using stirrers.

\section{Methods}

\subsection{Materials and Tools}

The CPO samples used in this study were obtained from PT. Syaukath Agro Lestari (Aceh, Indonesia). Isopropanol, ethanol, hydrochloric acid ( $\mathrm{HCl}$ ) and potassium hydroxide $(\mathrm{KOH})$ were purchased from a local distributor. The main equipment used was microwave (Panasonic, Indonesia) with 250 watts of power and a $25 \mathrm{~L}$ of capacity. The experimental setup used is illustrated in Figure 1.

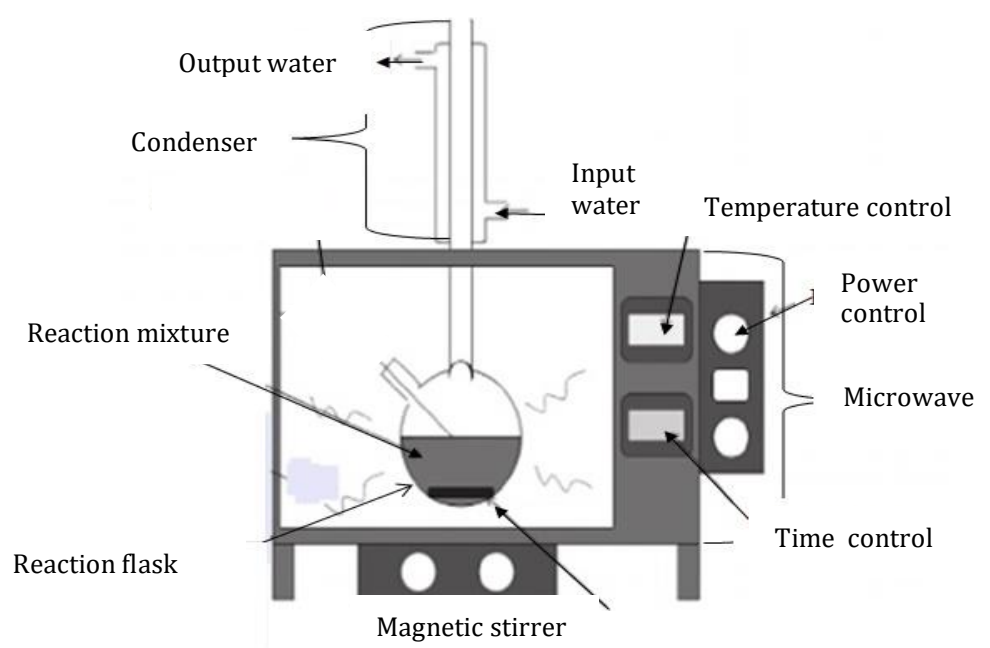

Figure 1 Experimental setup 


\subsection{Research Procedures}

The synthesis process of fatty acid isopropyl esters was carried out in several stages:

(1) the esterification process, (2) the transesterification process, and (3) product purification process.

\subsubsection{Esterification process}

Firstly, ethanol was mixed with $\mathrm{HCl}$ as an acid catalyst with a concentration of $1 \%$-w of the CPO used. Then, the mixture was reacted with CPO in a three-neck flask with a molar ratio of CPO to ethanol of 1:12. The three-neck flask was then attached to a microwave device equipped with a reflux condenser. The reaction was carried out for 5 minutes at temperature $70^{\circ} \mathrm{C}$, set on the micropower button. The resulting product (water at the bottom layer and esterified CPO at the top layer) was then separated using a separating funnel. The esterification progress was monitored in terms of the acid number of reaction product. The experimental results showed that this esterification reaction can reduce the acid number from 24.68 to $0.73 \mathrm{mg} \mathrm{KOH} / \mathrm{g}$.

\subsubsection{Transesterification process}

The molar ratios of CPO to isopropanol used in the transesterification process were $1: 3,1: 5,1: 7,1: 9,1: 11$, and $1: 13$. The catalyst used was $\mathrm{KOH}$, with catalyst concentrations of $0.10,0.15,0.20$, and 0.30 (\%-w of the CPO used). An alkaline-catalyzed transesterification process is the most common method because of the high reaction rates that coincide with this method. The mechanism of the reaction is reported in detail by Thoai et al. (2019). Firstly, KOH catalyst was dissolved and mixed with isopropanol until homogeneous. Then, the solution was fed into a three-neck flask that already contained esterified CPO. The threeneck flask was then attached to the microwave set. The transesterification reaction was carried out for 1,3 , and 5 minutes in a microwave at temperature $70^{\circ} \mathrm{C}$. The transesterification process using a magnetic stirrer was also conducted for comparison. For conventional transesterification, the molar ratio of CPO to isopropanol used was 1:11; the $\mathrm{KOH}$ catalyst concentration was $0.2 \%$; and the reaction was carried out for 90,120 , and 150 minutes.

\subsubsection{Purification process}

Transesterification products were put into a rotary evaporator. The evaporation process was carried out for 1 hour at a temperature of $105^{\circ} \mathrm{C}$ to separate the remaining isopropanol from the results of fatty acid isopropyl esters. The results of the evaporation were then put into a separating funnel and allowed to stand for 1 day to achieve complete separation between the two liquid phases. The top layer formed was fatty acid isopropyl esters as the main product, while the lower layer formed was glycerol as a by-product. Then the two layers were separated by removing the glycerol from the separating funnel. After that, the fatty acid isopropyl esters were washed using warm water at $50^{\circ} \mathrm{C}$. In the last step, the fatty acid isopropyl esters were heated at a temperature of $110^{\circ} \mathrm{C}$ for 30 minutes to remove the water content.

\subsection{Analysis of Result}

The experimental results were reported in terms of fatty acid isopropyl ester yield determined by Eq. (1):

$$
\text { Fatty acid isopropyl ester yield }=\frac{\text { Weight of fatty acid isopropyl ester }}{\text { Weight of CPO }} \times 100 \%
$$

The analysis of fatty acid isopropyl ester products was carried out qualitatively using a Fourier Transform Infrared Spectrophotometer (FTIR Shimadzu Prestige 6400). Analysis of the characteristics of fatty acid isopropyl ester product was done by determining the 
density using a pycnometer, viscosity using the Ostwald viscometer, and acid number using titration according to ASTM standard.

\section{Results and Discussion}

\subsection{Effect of Process Parameters}

Some important parameters that affect the yield produced in the transesterification process are the molar ratio of oil to alcohol, reaction time, and amount of catalyst. Figure 2 shows the effect of reaction time on the yield of fatty acid isopropyl esters-the longer the reaction time, the greater the yield. This happens because as processing time increases, transesterification process time also increases, such that the molecules between reactants collide over a longer period. Optimal processing time is needed to ensure complete diffusion between isopropanol, oil, and $\mathrm{KOH}$ catalyst. Perfect diffusion will make the process of forming fatty acid isopropyl esters more perfect (Milano et al., 2018). In this research, the highest yield was obtained at 5 minutes in all variations of the CPO to isopropanol molar ratio. Mahlinda et al. (2017) previously reported that the optimal reaction time was 4 minutes for in-situ transesterification of screw pine fruit seed oil with microwave assistance. However, the further effects of processing times that exceeded 5 minutes could not be observed due to limitations of the present experimental equipment.

The results also showed that the yield of fatty acid isopropyl ester increased with increasing molar ratios of isopropanol to CPO. Stoichiometrically, 1 mole of triglyceride requires 3 moles of alcohol to produce 3 moles of fatty acid isopropyl ester and 1 mole of glycerol. However, because the transesterification reaction is classified as a reversible reaction, excess alcohol and reactants are needed to shift the equilibrium towards the product (Chuah et al., 2015; Helmiyati and Anggraini, 2019). In this research, the highest yield $(80.5 \%)$ was obtained at a molar ratio of $1: 11$ in 5 minutes. However, the yield produced decreased at a CPO to isopropanol molar ratio of $1: 13$. This occurred because the higher molar ratio of CPO to isopropanol causes higher glycerol solubility; therefore, it can complicate the process of separation and purification of fatty acid isopropyl esters from glycerol (Milano et al., 2018). In addition, the excess glycerol in solution pushes the reaction process back to the reactants, which causes the yield of fatty acid isopropyl esters to decrease.

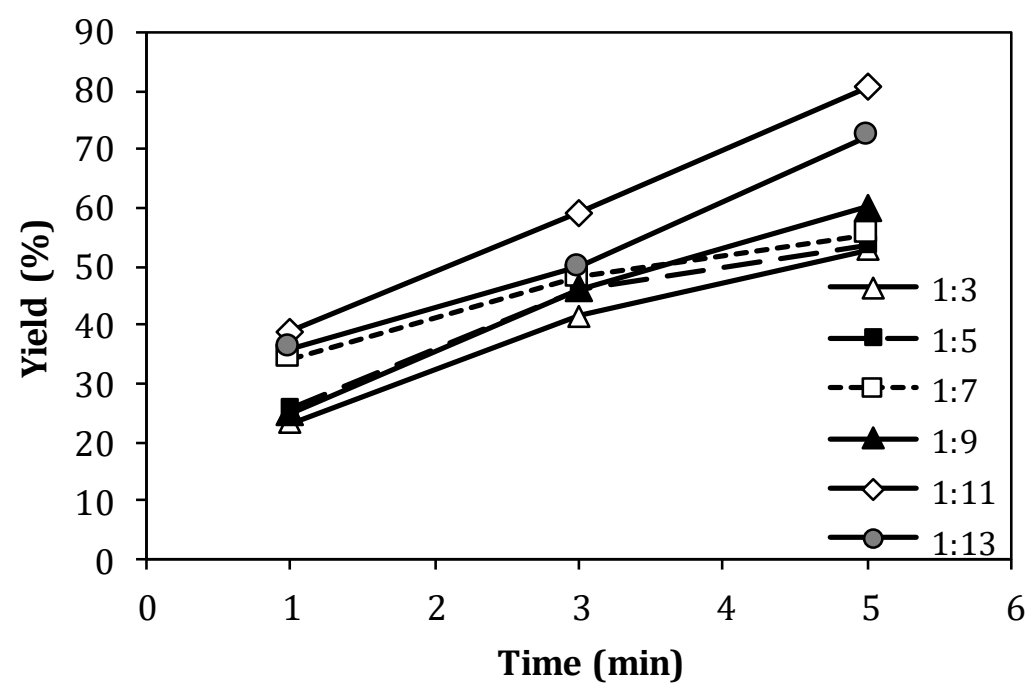

Figure 2 Effect of reaction time and molar ratio of CPO to isopropanol on yield of fatty acid isopropyl ester at catalyst concentration $0.2 \%$ 
A catalyst is a substance used to increase the rate of a reaction (Syamsuddin et al., 2016). Figure 3 shows the effects of KOH catalyst concentration on the yield of fatty acid isopropyl ester products. The use of catalysts in transesterification reactions can increase reaction rates. The experimental results showed that the greater the $\mathrm{KOH}$ catalyst concentration, the greater the amount of fatty acid isopropyl esters produced. Increases in catalyst amounts enhance the availability and number of catalytically active sites, thereby increasing the product yield (Hidayat et al., 2018). If the amount of catalyst is increased, the activation energy will decrease, so the reaction rate constant will be even greater. Large reaction rate constants will result in faster equilibrium reactions such that maximum reaction conversions will also be quickly achieved. However, at a catalyst concentration of $0.3 \%$, the yield produced decreases. This occurs because the addition of an excessive alkaline catalyst causes a saponification reaction between triglycerides and the catalyst. This reaction can reduce the yield of fatty acid isopropyl esters as a result of the triglycerides not being completely converted into fatty acid isopropyl esters but instead forming soap (Chuah et al., 2015). The use of an appropriate catalyst amount, as well as a correct choice of reaction conditions, can assist the system to gain the best process performance (Satriana et al., 2018).

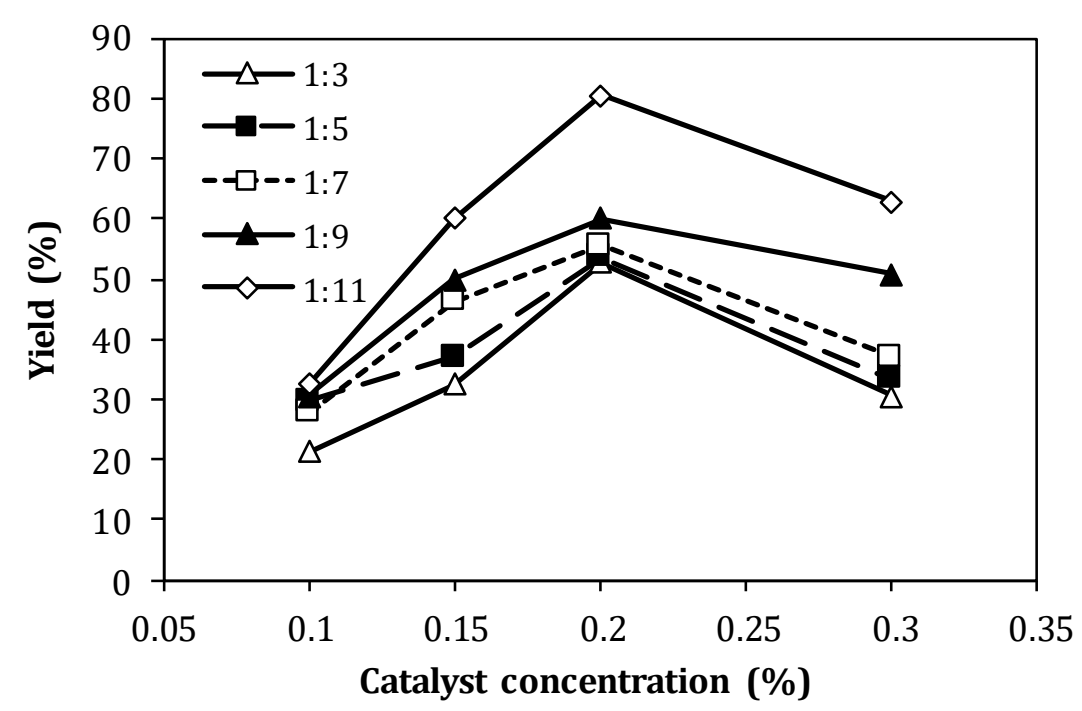

Figure 3 Effects of catalyst concentration and molar ratio of CPO to isopropanol on the yield of fatty acid isopropyl ester at reaction time 5 minutes

\subsection{Process Comparison}

The comparison of the transesterification process using microwaves and conventional transesterification using a stirrer at the molar ratio of CPO to isopropanol of 1:11 and catalyst concentration of $0.2 \%$ can be seen in Table 1 . In a short period of time, the yield generated in the transesterification process using microwaves was greater compared to conventional transesterification. In transesterification using microwaves, a maximum yield of $80.5 \%$ was produced in 5 minutes, whereas in conventional transesterification, the maximum yield of $72.2 \%$ was produced after 150 minutes. This result is in line with the research of Yu et al. (2017), which reported that maximum biodiesel yield obtained within 2.2 minutes using microwave radiation, whereas maximum biodiesel yield obtained within 60 minutes using conventional heating methods.

The use of microwaves as a source of heating provides direct energy transfer to the reaction mixture through a radiation mechanism instead of convection and conduction (Nayak et al., 2019). This result can be described in terms of a rapidly changing 
electromagnetic field that induces molecular rotation to polar compounds depending upon their dipole moment. The molecular rotation enhances the collision of molecules, which eventually reduces the inhibition constant and increases the affinity of the substrate to the active site of catalyst. It leads to an increase in the reaction rate, and the process is timeefficient. In addition, the heating process takes place from inside out; hence, the heat loss compared to the conventional process is minimal. Therefore, the use of microwaves consumes less than $10 \%$ of the energy to achieve the same yield as the conventional heating method (Patil et al., 2010). Meanwhile, heat is transferred by conduction and convection in conventional heating. Therefore, the transferred temperature is uneven and creates localized temperature gradients inside the reaction mixture. Overheating at the reactor vessel surface may cause decomposition of reactant, catalyst, and product of the reaction (Lidstrom et al., 2001; Panadare and Rathod, 2017).

Table 1 Comparison of the transesterification process using microwaves and conventional transesterification

\begin{tabular}{cccc}
\hline \multirow{2}{*}{ No } & \multirow{2}{*}{ Time (Minutes) } & \multicolumn{2}{c}{ Yield (\%) } \\
\cline { 3 - 4 } & & Microwave & Conventional \\
\hline 1 & 1 & 38.9 & - \\
2 & 3 & 59.2 & - \\
3 & 5 & 80.5 & - \\
4 & 90 & - & 34.2 \\
5 & 120 & - & 48.1 \\
6 & 150 & - & 72.2 \\
\hline
\end{tabular}

\subsection{FTIR Analysis Result}

The results of the functional group analysis in the form of FTIR spectrum can be seen in Figure 4. The FTIR results show that the hydroxide group $(-\mathrm{OH})$ as an alcohol group appears at $3,350 \mathrm{~cm}^{-1}$ in isopropanol. It is not found in CPO, but it is found in fatty acid isopropyl esters at $3,366 \mathrm{~cm}^{-1}$.

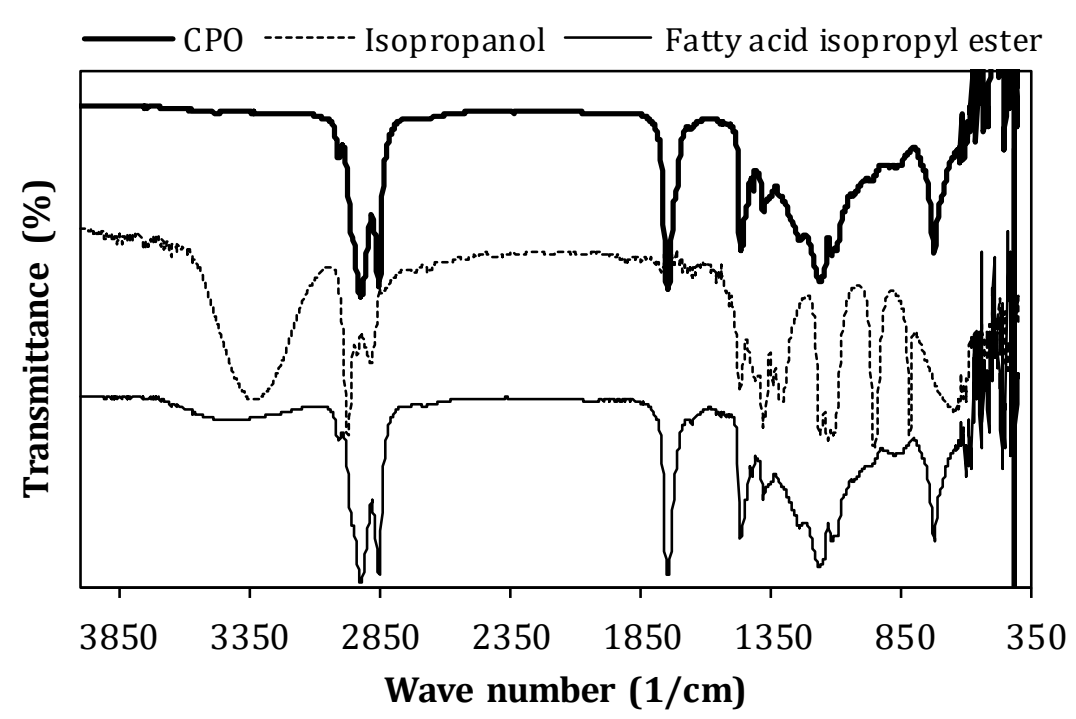

Figure 4 FTIR spectra of CPO and fatty acid isopropyl esters

The appearance of the $(-\mathrm{OH})$ in fatty acid isopropyl esters indicates that CPO has reacted with isopropanol. Fatty acid isopropyl esters produced from the transesterification 
reaction produce a product with a typical alkyl ester group. The $(\mathrm{C}-\mathrm{O})$ group found in fatty acid isopropyl esters has wavenumber at 1,115 $\mathrm{cm}^{-1}$, while in CPO they are found at 1,110 $\mathrm{cm}^{-1}$. The peak is included in the absorption area of 1,110-1,300 $\mathrm{cm}^{-1}$. The change from $1,110 \mathrm{~cm}^{-1}$ to $1115 \mathrm{~cm}^{-1}$ indicates that the triglycerides present in $\mathrm{CPO}$ have been converted to fatty acid isopropyl esters. The ester group $(C=0)$ also appears in $C P O$ at $1,742 \mathrm{~cm}^{-1}$, with the wavenumber at $1,743 \mathrm{~cm}^{-1}$ in fatty acid isopropyl esters. Another peak that shows the difference of fatty acid isopropyl esters with CPO is found at the wavenumber $1,647 \mathrm{~cm}^{-1} \mathrm{in}$ CPO and 1,651 $\mathrm{cm}^{-1}$ in fatty acid isopropyl esters. The peak is included in the absorption area of 1,600-1,700 $\mathrm{cm}^{-1}$, which shows the (C-C) group. Moreover, there is an isopropyl group peak with wavenumber $1,377 \mathrm{~cm}^{-1}$. A similar observation was reported for transesterification products derived from waste frying oil (Elkady et al., 2015; Yusuff et al., 2018).

\subsection{Characteristics of Fatty Acid Isopropyl Esters}

The characteristics of fatty acid ester isopropyl produced can be seen in Table 2. The comparison is done in accordance with the Indonesian National Standard (SNI) No. 71822015. The characteristics of fatty acids isopropyl esters produced were within the permissible limit of SNI.

Table 2 Characteristics of fatty acid isopropyl esters

\begin{tabular}{lcc}
\hline \multicolumn{1}{c}{ Parameters } & Study Results & SNI No. 7182-2015 \\
\hline Density $\left(\mathrm{kg} / \mathrm{m}^{3}\right)$ & $856-883$ & $850-890$ \\
Viscosity $\left(\mathrm{mm}^{2} / \mathrm{s}\right)$ & $3.29-5.68$ & $2.3-6$ \\
Acid number $(\mathrm{mg} \mathrm{KOH} / \mathrm{g})$ & $0.30-0.47$ & $\leq 0.5$ \\
\hline
\end{tabular}

\section{Conclusions}

The use of microwaves has been shown to intensify the synthesis process of fatty acid isopropyl esters. The highest yield of $80.5 \%$ of fatty acid isopropyl esters was obtained at the following condition: CPO to isopropanol molar ratio $1: 11$, catalyst concentration $0.2 \%$, and reaction time 5 minutes. The use of microwaves provided a higher yield of fatty acid isopropyl esters than conventional transesterification processes. The results of the FTIR analysis showed several specific functional groups in fatty acid isopropyl esters produced. The results of testing the characteristics of fatty acids isopropyl ester showed that viscosity, density, and acid number met the SNI No. 7182-2015 standard.

\section{Acknowledgements}

We would like to acknowledge the contributions of The Ministry of Research, Technology, and Higher Education of the Republic of Indonesia, which has funded this research (No. 61/UN11.2/PP/SP3/2019), and the Chemical Engineering Department of Universitas Syiah Kuala, which provided the research facility.

\section{References}

Cercado, A.P., Ballesteros, F.C., Capareda, S.C., 2018. Biodiesel from Three Microalgae Transesterification Processes using Different Homogenous Catalysts. International Journal of Technology, Volume 9(4), pp. 645-651

Chuah, L.F., Suzana, Y., Abdul, R.A.A., Awais, B., Jiri, J.K., Zamri, M.A., 2015. Intensification of Biodiesel Synthesis from Waste Cooking Oil (Palm Olein) in a Hydrodynamic Cavitation 
Reactor: Effect of Operating Parameters on Methyl Ester Conversion. Chemical Engineering and Processing, Volume 95, pp. 235-240

Dehghan, L., Golmakani, M.T., Hosseini, S.M.H., 2019. Optimization of Microwave-assisted Accelerated Transesterification of Inedible Olive Oil for Biodiesel Production. Renewable Energy, Volume 138, pp. 915-922

Elkady, M.F., Ahmed Z., Ola, B., 2015. Production of Biodiesel from Waste Vegetable Oil via KM Micromixer. Journal of Chemistry, Volume 2015, pp. 1-9

Encinar, J.M., Gonzalez, J.F., Martinez, G., Sanchez, N., Pardal, A., 2012. Soybean Oil Transesterification by the Use of a Microwave Flow System. Fuel, Volume 95, pp. 386393

Hidayat, A., Mukti, N.I.F., Handoko, B., Sutrisno, B., 2018. Biodiesel Production from Rice Bran Oil over Modified Natural Zeolite Catalyst. International Journal of Technology. Volume 9(2), pp. 400-411

Helmiyati, Anggraini, Y., 2019. Nanocomposite Comprising Cellulose and Nanomagnetite as Heterogeneous Catalysts for the Synthesis of Biodiesel from Oleic Acid. International Journal of Technology, Volume 10(4), pp. 798-807

Laosuttiwong, T., Ngaosuwan, K., Kiatkittipong, W., Wongsawaeng, D., Kim-Lohsoontorn, P., Assabumrungrat, S., 2018. Performance Comparison of Different Cavitation Reactors for Biodiesel Production via Transesterification of Palm Oil. Journal of Cleaner Production, Volume 205, pp. 1094-1101

Lidstrom, P., Tiarney, J., Wathey, B., Westman, J., 2001. Microwave Assisted Organic Synthesis-A Review. Tetrahedron, Volume 57(45), pp. 9225-9283

Mahlinda, Supardan M.D., Husin H., Riza M., Muslim A., 2017. A Comparative Study of Biodiesel Production from Screw Pine Fruit Seed: Using Ultrasound and Microwave Assistance in In-situ Transesterification. Journal of Engineering Science and Technology, Volume 12(12), 3412-3425

Milano, J., Hwai, C.O., Masjuki, H.H., Silitonga, A.S., Wei, H.C., Kusumo, F., Dharma, S., Sebayang, A.H., 2018. Optimization of Biodiesel Production by Microwave Irradiationassisted Transesterification for Waste Cooking Oil-Calophyllum Inophyllum Oil via Response Surface Methodology. Energy Conversion and Management, Volume 158, pp. 400-415

Nayak, S.N., Bhasin, C.P., Nayak, M.G., 2019. A Review on Microwave-assisted Transesterification Processes using Various Catalytic and Non-catalytic Systems. Renewable Energy, Volume 143, pp. 1366-1387

Patil, P.D., Gude, V.G., Camacho, L.M., Deng, S., 2010. Microwave-assisted Catalytic Transesterification of Camelina Sativa Oil. Energy \& Fuels, Volume 24(2), pp. 12981304

Panadare, D.C., Rathod, V.K., 2017. Microwave Assisted Enzymatic Synthesis of Biodiesel with Waste Cooking Oil and Dimethyl Carbonate. Journal of Molecular Catalysis B: Enzymatic, Volume 133(S1), pp. S518-S524

Satriana, Arpi, N., Supardan, M.D., Gustina, R.T., Mustapha, W.A.W., 2018. Low-Temperature Glycerolysis of Avocado Oil. In: AIP Conference Proceedings, Volume 1940, 020100

Seo, E.J., Yeon, Y.J., Seo, J.H., Lee, J.H., Bongol, J.P., Oh, Y., Moon Park, J., Lim, S.M., Lee, C.G., Park, J.B., 2018. Enzyme/whole-cell Biotransformation of Plant Oils, Yeast Derived Oils, and Microalgae Fatty Acid Methyl Esters into n-nonanoic Acid, 9-hydroxynonanoic acid, and 1,9-nonanedioic Acid. Bioresource Technology, Volume 251, pp. 288-294

Supardan, M.D., Fahrizal, Moulana, R., Safrida, D., Satriana, Mustapha, W.A.W., 2017. Optimization of Process Parameter Conditions for Biodiesel Production by Reactive 
Extraction of Jatropha Seeds. Journal of Engineering Science and Technology, Volume 12(3), pp. 847-859

Syamsuddin, Y., Murat, M.N., Hameed, B.H., 2016. Synthesis of Fatty Acid Methyl Ester from the Transesterification of High- and Low-acid-content Crude Palm Oil (Elaeis guineensis) and Karanja oil (Pongamia pinnata) over a Calcium Anthanum Aluminum Mixed-oxides Catalyst. Bioresource Technology, Volume 214, pp. 248-252

Teo, C.L., Ani, I., 2014. Evaluation of Direct Transesterification of Microalgae using Microwave Irradiation. Bioresource Technology, Volume 174, pp. 281-286

Thoai, D.N., Chanakaewsomboon, I., Prasertsit, K., Photaworn, S., Tongurai, C., 2019. A Novel Inspection of Mechanisms in Conversion of Refined Palm Oil to Biodiesel with Alkaline Catalyst. Fuel, Volume 256, pp. 1-9

Ye, W., Yujie, G., Hui, D., Mingchao, L., Shejiang, L., Xu, H., Jinlong, Q., 2016. Kinetics of Transesterification of Palm Oil under Conventional Heating and Microwave Irradiation, using $\mathrm{CaO}$ as Heterogeneous Catalyst. Fuel, Volume 180, pp. 574-579

Yu, G.W., Nie, J., Lu, L.G., Wang, S.P., Li, Z.G., Lee, M.R., 2017. Transesterification of Soybean Oil by using the Synergistic Microwave Ultrasonic Irradiation. Ultrasonics Sonochemistry, Volume 39, pp. 281-290

Yusuff, A.S., Adeniyi, O.D., Olutoye, M.A., Akpan, U.G., 2018. Development and Characterization of a Composite Anthill-chicken Eggshell Catalyst for Biodiesel Production from Waste Frying Oil. International Journal of Technology, Volume 9(1), pp. 110-119 